\title{
Coping strategies of parents of children with autism spectrum disorder: a systematic review
}

Christelle Vernhet ${ }^{1,2,3}$, Florine Dellapiazza ${ }^{1,2,3}$, Nathalie Blanc ${ }^{2}, \mathrm{PhD}$, Florence Cousson-Gélie ${ }^{2}, \mathrm{PhD}$, Stéphanie Miot $^{3}, \mathrm{MD}, \mathrm{PhD}$, Herbert Roeyers ${ }^{4}, \mathrm{PhD}$, Amaria Baghdadli1 ${ }^{1,3}, \mathrm{MD}, \mathrm{PhD}$

1 Centre Ressources Autisme, CHU, F-34000 Montpellier, France;

2 Univ. Paul Valéry Montpellier 3, Univ. Montpellier, EPSYLON EA 4556, F34000, Montpellier, France;

3 Centre de Recherche en Épidémiologie et Santé des Populations, UMR1178, INSERM, Paris, France;

4 Department of Experimental Clinical and Health Psychology, Ghent University, Ghent, Belgium.

\section{Corresponding author:}

Christelle VERNHET, Centre Ressources Autisme, CHU Montpellier, 39 Avenue Charles Flahault, 34295

Montpellier cedex 05, France. Tél: +33467330861, Fax: +33467330832 E-mail: c-vernhet@chu-montpellier.fr.

\begin{abstract}
To deal with stress, parents of children with ASD use coping strategies that help to tackle the challenging situations of raising their child. This systematic review examine parental coping strategies questionnaires, factors which influence this coping strategies, interactions between this strategies and perceived stress and their impact on parental quality of life. According to PRISMA guidelines, an electronic search was conducted on Medline, PsycInfo and Eric: 156 articles was identified and 11 studies were selected. Many types of self-reported questionnaires were used to assess parental coping strategies. Studies highlighted parents of a child with ASD used more avoidance strategies and less social support seeking strategies than those of typical children. Furthermore, problem-focused coping protects parental stress and quality of life, that on the contrary, emotion-focused coping is a risk factor for alteration. Our systematic review illustrates the need to adapt psychoeducation interventions for parents of children with ASD.
\end{abstract}

Keywords: Autism, Parents, Children, Coping, Systematic review

\section{Aknowledgments}

The authors would like to thank Cécile Michelon for participating in the data analyses and help in the article submission 


\section{Introduction}

Autism Spectrum Disorder (ASD) is a neurodevelopmental disorder characterized by the association of abnormalities in social interaction and communication with restricted or repetitive patterns of thought and behavior [1]. This condition is particularly severe and long-lasting relative to other developmental disorders and considerably affects family functioning. The number of studies published about the impact of ASD on parents has increased in the last two decades and there is now a consensus that parents with a child with ASD experience more stress than those of typical children [2-5]. Parental stress is defined as a state perceived by parents resulting from demands associated with their parenting role [6,7]. These dimensions have specifically been explored in ASD, as parental stress is commonly related to the characteristics of both the child and the parent [8]. The ASD literature shows that parental stress is mainly influenced by the child's behavioral problems and deficits in socialization and communication [9-11]. In ASD, however, parental stress is also related to parental characteristics (e.g., age, gender, and personality traits) [12,13]. It has also been suggested that having a child with ASD may not only be linked to emotional variables (e.g., stress) but also many social, physical, and financial variables, likely altering the parental quality of life [11,14-16].

Parents of children with ASD use coping strategies that help tackle the challenging situations of raising their child $[17,18]$. The most widely cited definition of coping is: "constantly changing cognitive and behavioral efforts to manage specific external and/or internal demands that are appraised as taxing or exceeding the resources of the person" [19]. Two dimensions of coping strategies have initially been proposed [20]: problem-focused coping (which involves taking action on the problem causing distress) and emotion-focused coping (which aims to manage emotional distress associated with the problem). Arriving to a consensus on the classification of coping strategies is a large challenge for researchers [21]. Coping strategies are measured using highly diverse selfreporting questionnaires. Such diversity in coping measurement tools can be explained by the complexity of this area of research and the resulting lack of consensus among researchers. Indeed, although various types of coping are now quite well-defined, their diversity complicates their evaluation and measurement. Moreover, there has been little assessment in the literature of the relevance of the various coping strategy questionnaires used. It was suggested in a study using a multifactorial approach [22] that coping strategies interact not only with other transactional variables, such as perceived stress, but also several environmental and individual factors (“antecedents"), which influence the quality of life. Antecedents, such as parental age and gender and marital and professional status, have been described in the parents of children with ASD [23]. In a literature review of coping strategies of parents of children with ASD, Lai and Oei [24] described problem-focused coping and social support as the most widely used coping strategies and found links between these strategies and parental and child characteristics. However, this study was not a systematic review and didn't allow assessment of the strengths and weaknesses of the questionnaires used to measure parental coping.

Despite growing interest in understanding the coping strategies used by the parents of children with ASD, no systematic review has been published on this topic concerning the types of strategies, the tools used, or the links between these strategies and other variables. For this systematic review, we followed the PRISMA standards, a 27-item checklist and a five-phase process including: 1) formulate the questions, 2) identify the relevant studies, 3) assess the quality of the studies, 4) summarize the evidence, and 5) interpret the findings. The results were examined to answer the four following questions concerning coping strategies used by parents of children with 
ASD: a) What tools are used to measure coping strategies and what are their strengths and weaknesses? b) What environmental and individual factors are likely to influence parental coping strategies? c) What are the interactions between parental coping strategies and perceived stress? d) What is the impact of parental coping strategies on their quality of life?

2. Method

\subsection{Research procedures}

We performed a literature search for articles published in English or French in Medline, Psycinfo, and ERIC, using a combination of keywords relevant to ASD (“Autism Spectrum Disorders” or "Child developmental disorder, pervasive"), coping (“coping behavior" or "coping”) and "parents". These words were extracted from the thesaurus of the database. For example, "Autism Spectrum Disorders" or "Child developmental disorder, pervasive" refer to all terms used for autism: autism, autism spectrum disorder, Asperger syndrome, pervasive developmental disorders, autistic disorder, etc. The algorithm used was 1) "Child developmental disorder, pervasive and coping and parents" in Medline and 2) "Autism Spectrum Disorders and coping behavior and parents" in Psycinfo and ERIC. The search was restricted to the most recent studies, published between January $1^{\text {st }} 2006$ and July $1^{\text {st }} 2017$, to ensure that the studies covered a reasonable scope and were up-to-date.

\subsection{Inclusion and exclusion criteria}

The studies were selected according to the following inclusion criteria: 1) quantitative studies (to facilitate data extraction and statistical analysis); 2) original research articles; 3) samples including parents having a child with ASD diagnosed according to ICD-10, DSM-IV-TR, DSM-5 criteria or ADI-R; 4) children aged under 18 years (to avoid mixing the very diverse situations of children/adolescents and adults from the perspective of the family situation); and 5) standardized and validated questionnaires used to examine parental coping strategies. The validation of the questionnaires was determined in each study and the questionnaires were validated in the country of use. The exclusion criteria were: 1) studies focusing on parental training programs or validation tools, 2) samples including parents of children with a condition other than ASD, and 3) interventional and pharmacological studies.

Abstracts were read independently by two of the authors (FD \& CV), who selected them if they fulfilled the inclusion criteria. If consensus was not reached, the abstract was set aside for further evaluation. Full-text articles of selected abstracts were then reviewed by FD \& CV and inclusion was based on consensus between the two authors.

\subsection{Data extraction}

Data extraction from full texts was organized into the following sections: 1) participant characteristics: number of subjects in each group, number of fathers, mothers, or other caregivers, age, gender, marital status, employment status; 2) child characteristics: age, diagnosis, and diagnostic tool; 3) tool used to measure coping; and 4) statistical analysis and main results.

\subsection{Quality appraisal}

Multiple quality criteria were used to systematically evaluate each study. They were created on the basis of "The STROBE Reporting Guidelines for writing and reading observational studies in epidemiology" [25] and the "Critical review form - Quantitative studies" [26]. New criteria were developed to more precisely evaluate the 
studies. Our grid consists of 18 items, including 12 from STROBE and 2 from Mac Dermid. We added four additional items related to the description and relevance of the tools (in association with our first aim).

\section{[INSERT FIGURE 1]}

For each criterion, the authors assigned two points to fully respected criteria, one point to partially respected criteria, and no points to non-respected criteria. A total score was calculated for each study. Studies were then rated as poor (total score less than 12 points), fair (total score between 13 and 24 points), good (total score between 25 and 30 points), or excellent (total score between 30 and 36 points), based on the scores obtained. Studies were rated independently by two reviewers (CV and FD). The Cohen's Kappa coefficient was calculated, and inter-rater reliability was $95 \%$.

3. Results

\subsection{Database search}

Of the 156 articles identified in the database search, 125 remained after duplicates were removed. After screening the titles and abstracts, 75 were excluded because they did not meet the inclusion criteria (mainly because they were not quantitative studies). The texts of 50 articles were then fully screened according to the inclusion and exclusion criteria. Finally, 11 papers were selected for the review. Figure 1 illustrates the study selection steps in more detail.

\section{[INSERT FIGURE 2]}

\subsection{Study quality}

The quality rating was "fair" for one study [27], "good" for five [28-32], and "excellent" for the remaining five [33-37].

\subsection{Participant characteristics}

Overall, the sample size of the 11 selected studies was 1,388 parents, who were mainly mothers $(\mathrm{n}=$ 1,080, $77.8 \%$ versus 308 fathers, $22.2 \%$ ). The mean parental age in the 11 studies was from 30.7 to 46.1 years. Marital status was reported in nine studies (60 to 100\% of parents were married) and employment status in eight ( 30 to $73.3 \%$ of parents were employed). The mean children's age in the total sample was from 2.36 to 14.10 years. The participant characteristics are shown in Table 1.

\section{[INSERT TABLE 1]}

\subsection{Coping questionnaires}

The authors used self-administered questionnaires to assess parents' coping in the 11 selected studies. Below, we describe the questionnaires according to their use.

Ways of Coping Questionnaire (WCQ) or Ways of Coping Checklist (WCC-R) [33,30,37]

Three studies used the WCQ [38] or WCC-R [39], also referred to as the WCC. In these studies, the original instructions were revised to allow answers to specific stressors related to caring for a child with ASD, using a four-point scale. Pisula and Kossakowska [37] and Dardas and Ahmad [30] used this 66-item questionnaire divided into eight dimensions: confrontive coping, distancing, self-controlling, seeking social support, accepting 
responsibility, escape-avoidance, planful problem-solving, and positive reappraisal. The internal consistency reliability coefficients ranged from 0.68 to 0.79 for the eight subscales.

Cappe et al. [33] used the French version of the WCC-R [39], which is an adapted and abridged version of the WCC of Vitaliano et al., composed to 27 items [40]. The findings suggest a three-factor model and three sub-scores were calculated for each of the following dimensions: problem-solving strategies, emotion-focused strategies, and social support-seeking. The Cronbach's alpha coefficients were $0.76,0.73$, and 0.76 for each dimension, respectively.

\section{Coping Orientations to Problems Experienced (COPE) and Brief COPE [28,29,36]}

Among the 11 selected studies, three used the COPE [41] or an abbreviated version, the Brief COPE [42]. Participants were asked about the specific stressful situation of raising a child with ASD on a four-point scale.

Carter et al. [29] used a 60-item version in which parents report the degree of their use of coping strategies. Two total coping scores were determined: problem-focused coping and emotion-focused coping. The internal consistency of problem-focused coping ranged from 0.88 to 0.89 , and that of emotion-focused coping from 0.74 to 0.77 .

The Brief COPE is a 28 -item self-report that measures how often parents use a particular coping strategy when they experience a stressful event. In his study, Benson [28] used four coping dimensions extracted from his previous research [17]: engagement, disengagement, distraction, and cognitive reframing. Inter-item reliabilities for the four indices across assessments ranged from 0.84 to 0.86 for engagement, 0.78 to 0.82 for disengagement, 0.73 to 0.76 for distraction, and 0.74 to 0.77 for cognitive reframing. Lai et al. [36] used four sub-domains derived from Hastings et al. [43]: active avoidance coping, problem-focused coping, positive coping, and religious/denial coping. Internal consistency evaluations of the Brief COPE total and subscale scores were adequate, with Cronbach's alpha coefficients of 0.92 (Brief COPE total), 0.76 (active avoidance coping), 0.89 (problem-focused coping), 0.83 (positive coping), and 0.69 (religious/denial coping).

Simplified Coping Style Questionnaire (SCSQ) [35,32]

The two articles assessing coping strategies in Chinese parents of children with ASD [35,32] used the SCSQ [44]. The participants were asked about a generic stressful situation. This scale includes 20 items classified in two dimensions: positive/active coping and negative coping. All items are rated on a four-point scale. The Cronbach's alpha coefficient for positive/active coping and negative coping were 0.89 and 0.78 , respectively.

\section{Coping Inventory for Stressful Situations (CISS) [34]}

Dabrowska and Pisula [34] used the CISS [45], through which parents can assess their reactions when they are faced with a common stressful situation, using a five-point scale. This 48 -item scale has three dimensions: task-oriented coping, emotion-oriented coping, and avoidance-oriented coping (by social diversion and distraction). For Endler and Parker, avoidance by social diversion and avoidance by distraction were similar to social support coping. We called "avoidance by social diversion" and "avoidance by distraction" "social-support seeking" in our results to avoid confusion. Reliability coefficients were 0.58 for distraction, 0.61 for social distraction, 0.70 for avoidance-oriented coping, 0.76 for emotion-oriented coping, and 0.81 for task-oriented coping. 


\section{Coping Strategy Inventory (CSI) [27]}

Luque Salas et al. [27] used the CSI to evaluate the coping strategy of parents. The CSI was created by Tobin et al. [46] and adapted to Spanish by Cano et al. [47]. This version of the questionnaire consists of 40 items classified in eight dimensions: problem solving, self-criticism, expressing emotions, wishful thinking, social support, cognitive restructuring, problem avoidance, and social withdrawal. Parents respond about their reactions to a specific stressful situation while caring for their child, using a five-point Likert scale. The Cronbach's coefficient alphas ranged from 0.63 to 0.70 .

\section{Cognitive Emotion Regulation Questionnaire (CERQ) [31]}

Rayan and Ahmad [31] used the CERQ, created by Garnefski et al. [48], to measure conscious cognitive coping strategies for a generic stressful situation. The CERQ includes 36 items which are measured on a five-point Likert scale. Cronbach's coefficient alpha was 0.85. In their study, Rayan and Ahmad used the Positive Reappraisal Coping (PRC), which is a subscale of the CERQ.

\subsection{Coping of parents of children with ASD}

Based on the results of the 11 selected studies, we explore below the links between coping and 1) "antecedents": a stressful event (raising a child with ASD), age of the parents, parents' gender and sense of coherence, 2) perceived stress, and 3) quality of life.

\subsubsection{Link between coping and antecedents}

\section{Link between coping and a stressful event}

Three articles compared the coping strategies of parents of children with ASD to those with children with typical development. Lai et al. [36] suggested that parents of children with ASD use more active-avoidance coping than parents of typical children $\left(F=4.44, p<0.05, \eta^{2}=0.04\right)$. Pisula and Kossakowska [37] obtained similar results, with the parents of children with ASD having higher scores for escape-avoidance coping $(\mathrm{F}=4.69, \mathrm{p}<$ 0.03, $\eta^{2}=0.04$ ) than those of typical children. Dabrowska and Pisula [34] reported lower scores for social-support seeking among parents of children with ASD than those of typical children $\left(F=4.255, p<0.05, \eta^{2}=0.05\right)$.

Link between coping and parents' age

Salas et al. [27] showed correlations between two coping strategies and parents' age. They found a negative correlation between social support strategies $(r=-0.25, \mathrm{p}<0.001)$ and cognitive-restructuring strategies $(\mathrm{r}=-0.18, \mathrm{p}<0.05)$ and parental age.

\section{Link between coping and parents' gender}

Among the selected studies, four explored the specific coping strategies of mothers and fathers [34,36,37]. Only two found significant differences. The study of Dabrowska and Pisula [34] showed that mothers use more emotion-oriented coping $(\mathrm{F}=10.938, \mathrm{p}<0.01)$ and coping by social diversion $(\mathrm{F}=10.161, \mathrm{p}<0.01)$ than fathers. That of Luque Salas et al. [27] showed that mothers used more expressing-emotion strategies $(\mathrm{t}=4.08, \mathrm{p}<0.001)$ and social-support strategies $(\mathrm{t}=2.19, \mathrm{p}<0.05)$ than fathers, and fathers used more problem-avoidance strategies $(\mathrm{t}=2.29, \mathrm{p}<0.05)$ than mothers.

\section{Link between coping and sense of coherence}


The sense of coherence (SOC) is defined [49] as " a global orientation that expresses the extent to which one has a pervasive, enduring though dynamic feeling of confidence that (a) the stimuli deriving from one's internal and external environments in the course of living and structured, predictable, and explicable (comprehensibility); (b) the resources are available to one to meet the demands posed by these stimuli (manageability); (c) these demands are challenges worthy of investment and engagement (meaningfulness)', Among the selected studies, only that published by Pisula and Kossakowska [37] examines the link between coping and SOC measured by the Polish-adapted version of the Orientation to Life Questionnaire [50]. Alpha reliabilities ranged from 0.84 to 0.93 . Among parents of children with ASD, the highest SOC correlation coefficients were obtained for accepting responsibility and distancing. The dimension of accepting responsibility negatively correlated with total SOC $(r=-0.462, \mathrm{p}<0.01)$, whereas the use of distancing positively correlated $(\mathrm{r}=0.331, \mathrm{p}$ $<0.05)$. Positive correlations were also found between SOC and self-controlling $(r=0.273, p<0.05)$ and seeking social support $(\mathrm{r}=0.276, \mathrm{p}<0.05)$. Thus, the higher the parents' SOC, the more they used distancing, selfcontrolling, and social-support seeking and the less they use accepting responsibility.

\subsubsection{Link between coping and perceived stress}

Several selected studies investigated the link between coping and parental stress measured with different questionnaires assessing several dimensions of stress (stress proliferation, perceived stress as a threat and a loss or as a challenge, and global parental stress): the Effects of the Situation Questionnaire [51], the Appraisal of Life Events Scale [52], the Holroyd's 66-item Questionnaire of Resources and Stress [53], the Parenting Stress Index Short Form [54], and the Depression, Anxiety, and Stress Scale (DASS21) [55] (Table 2).

\section{[INSERT TABLE 2]}

Of the 11 studies selected, five focused on the link between coping and stress. Three highlighted the negative effect of emotion-focused coping on stress. In the Cappe et al. study [33], parents who used emotionfocused coping perceived their experiences as a threat and a loss. In that of Dabrowska and Pisula [34], there was also a link between parental stress and coping in which the more parents used coping strategies, the higher their stress levels became. Wang et al. [32] found the same results with negative coping. On the contrary, according to these researchers, active coping has a positive effect on parental stress as their stress levels become lower with repeated use of this type of coping strategy. In addition, Cappe et al. [33] demonstrated that parents who use problem-focused coping perceived their experiences as a challenge. Benson [28] found three significant effects of coping strategies on stress proliferation: use of disengagement, engagement, and cognitive reframing were related to an increase in stress proliferation. Finally, in the study of Rayan and Ahmad [31], the use of positive reappraisal coping by parents lessened their stress.

\subsubsection{Link between coping and quality of life}

Among the selected studies, two examined the effect of coping on parents' quality of life.

Cappe et al. [33] developed a quality of life scale to assess the consequences of ASD on the parents' life in eight dimensions: daily life activities, job and professional relationships, social activities and relationships, family activities and relationships, parent-child relationships, well-being, and overall quality of life. For each dimension, higher scores reflected greater difficulties for the parents. Many links were also found between coping and quality of life (Table 3). 


\section{[INSERT TABLE 3]}

The significant correlations found between problem-focused coping and parental quality of life were mostly negative. Thus, the more parents used problem-focused coping, the better their relationship with their child became and the more they felt fulfilled. Conversely, significant correlations between emotion-focused coping and quality of life were positive: the more parents used this type of strategy, the poorer their quality of life became.

In their study, Dardas and Ahmad [30] assessed the Quality of Life (QoL) of parents of a child with ASD using the World Health Organization Quality of Life Assessment-Brief self-administered instrument [56]. It contains twenty-six items rated on a five-point scale. A total score is obtained and used for the evaluation. The Cronbach's alpha coefficient was 0.93 . Results show a mediating effect of accepting responsibility between stress and $\mathrm{QoL}(\beta=-0.046, \mathrm{p}>0.05)$. This coping strategy had an indirect negative effect. On the other hand, the authors revealed that only seeking social support $\left(R^{2}=0.40, p<0.05\right)$ and escape avoidance $\left(R^{2}=0.41, p<0.01\right)$ were moderators in the relationship between stress and QoL. This indicates that the effect of stress on quality of life increases as the use of these two types of coping strategies increases.

\section{Discussion}

This systematic review examined coping strategies among the parents of children with ASD. Each step of the process was performed independently by at least two of the authors. The quality appraisal of the reviewed papers showed that they fulfilled most of the required criteria (i.e. relevance of the topic, methodological quality, and analysis of the results) and consequently, that their results were consistent.

The first aim of this review was to study the tools used to assess parents' coping strategies. We identified eight self-reported questionnaires of which the differences made it difficult to compare studies. Analysis of the eight questionnaires made it possible to the identify strengths and weaknesses of each. First, the CISS, SCSQ, and CERQ study coping strategies experienced during a generic stress situation, whereas the rest (i.e. the WCQ, WCC$\mathrm{R}$, COPE, or COPE with CSI) evaluate coping strategies experienced during the specific situation of raising a child with ASD. The use of distinct coping strategies by parents of children with ASD suggests that their assessment by a situation-specific questionnaire is more relevant. Second, the reliability of the tools (analyzed through Cronbach coefficients (Cronbach, 1951)) is variable: insufficient for the CSI and CISS, and good for the other tools (i.e. the WCQ, WCC-R, COPE or Brief COPE, SCSQ, and CERQ). Third, none of the questionnaires take into account the age of the child in the assessment of parental coping strategies. Finally, only the SCSQ, WCC-R, and Brief COPE questionnaires contain a small number of items, which favors the participation of parents, whereas the other questionnaires are long (between 36 and 66 items). In summary, only the WCC-R and the Brief COPE are adequate in terms of specificity, reliability, and number of items to be recommended to study parental coping strategies in ASD

The second aim was to explore which coping strategies were used by parents. The reviewed articles, which included a control group showed, the impact of a stressful event - raising a child with ASD - on the use of coping strategies. Thus, parents of a child with ASD used more avoidance strategies than those of typical children. Other investigators have reported similar results in previous studies [43,18]. It seems that avoidance is a strategy typically used to cope with a stressful situation, such as the announcement of an illness. Conversely, parents of children with ASD used less social-support seeking strategies than those of typical children. Some parents describe 
strained relations with some friends or family members following the announcement of the diagnosis of their child [58]. Thus, it is probably difficult for them to reach out to other people for support. Understanding the specificity of coping strategies used by the parents of children with ASD probably requires comparing them to those with children with typical development. Moreover, some authors have suggested that parents of children with ASD don't use the same coping strategies as parents of children with other neurodevelopmental disorders [59], although there are conflicting results in the literature. Wang et al. [59] reported that the use of avoidance coping is less common among parents of children with ASD, whereas Lai et al. [36] and Pisula and Kossakowska [37] reported the opposite. There is more agreement about the reduced use of social-support seeking strategies by parents of children with ASD relative to parents of children with other developmental disorders. These divergent findings in the existing literature suggest the need for further studies of coping strategies specifically used by parents of children with ASD.

Our review showed that sociodemographic factors also influenced the coping strategies of parents of children with ASD. Among the reviewed papers, four studies examined differences between mothers and fathers, but only two identified an effect of parental gender [34,27]. In these studies, mothers used more emotion-focused coping and social-support seeking than fathers. This is consistent with other studies, which have shown that women used more emotion-focused coping and sought help from theirs friends to cope with stress [60,61]. Although two studies showed differences between mothers and fathers, these differences were not clearly distinct. This confirms findings from other studies, as some have shown gender differences in the use of coping strategies $[62,16]$, whereas others have not $[63,43]$. These discrepancies highlight the need for further well-designed studies. In addition, the proportion of fathers in our total review sample was too limited to analyze coping strategy differences across gender, and other studies should recruit more fathers of children with ASD. Among the individual factors that influence coping strategies, one of the reviewed studies [37] highlighted the central role of the sense of coherence (SOC). Studies $[64,65]$ found that parents who have a low SOC tend to blame themselves when they experience stressful situations related to caring for their child, whereas those with a higher SOC used more social-support seeking and self-controlling strategies. Thus, when parents perceive their life and events as understandable, manageable, and meaningful they are able to use efficient coping strategies. However, the small number of studies exploring the link between SOC and parents' coping strategies in ASD limits the generalization of these findings, whereas they might be useful to improve parental training and support.

Our systematic review also highlights the links between parental coping strategies and their stress and quality of life, as in previous studies $[43,66]$. It has been shown that increasing use of problem-focused strategies by parents lowered their stress levels, whereas increasing use of emotion-focused strategies increased them $[33,34,32]$. These results also suggest that problem-focused coping protects parental quality of life and that, on the contrary, emotion-focused coping is a risk factor for altercation [33]. In one of the reviewed studies, coping strategies were addressed in terms of mediators and moderators involved in the connection between stress and quality of life [30], suggesting that the interaction between psychosocial variables be taken into account in the assessment of coping strategies. Other researchers have also shown that some coping strategies are more effective in coping with parental stress of a child with autism [67,2]. Indeed, parents who use emotion-based coping strategies, such as escaping from the problem or distancing, have more depressive symptoms, feel more socially isolated, and experience more problems in their relationship with their children. On the contrary, using coping 
strategies that focus on the problem or on the search for social support reduces negative adaptive outcomes. These coping strategies are more effective at decreasing the negative effect of stress on the quality of life.

One important limit of the studies we reviewed is that they considered neither the age of the child nor the severity of his autistic symptoms or challenging behaviors, whereas these factors could influence coping strategies $[68-70,5,66]$. The impact of these variables will need to be examined in future studies.

\section{Conclusion and clinical implications}

Our systematic review illustrates the need for psychoeducation interventions for parents of children with ASD. Clinicians should assess parental stress to better adapt such care. Studies have shown that parental stress is greater for parents of children with ASD than other parents. Consequently, we should assess their quality of life to establish which areas are most affected by the child's disorder. The results of our review highlight that parents use coping strategies to cope with their child's disorder. As Benson [28] stressed, psychotherapists should be aware of the coping strategies that parents of children with ASD use. Indeed, the results reveal a negative impact of emotionfocused strategies on parental stress. It is therefore important during parental counseling to teach them how to manage their emotions. In contrast, the results show that problem-focused strategies have a positive impact on parental stress and quality of life. Thus, therapists should support parents in problem solving by proposing solutions adapted to their child's functioning, as shown by Cappe et al. [33]. In addition, we also observed that social-support seeking is an effective strategy for parents of children with ASD. It is therefore our responsibility to help such parents to identify people who can support them, either in their family or through an association or professionals, as suggested by Carter et al. [29]. Finally, although differences between how fathers and mothers cope with their child's disorder must still be explored, clinicians should aid both parents and pay attention to their inter-individual differences.

\section{Compliance with ethical standards}

Conflict of interest: The authors declare that they have no conflict of interest.

\section{References}

1. American Psychiatric Association (2013) Diagnostic and statistical manual of mental disorders (DSM-5®). American Psychiatric Pub,

2. Dunn ME, Burbine T, Bowers CA, Tantleff-Dunn S (2001) Moderators of stress in parents of children with autism. Community Ment Health J 37 (1):39-52

3. Hayes SA, Watson SL (2013) The impact of parenting stress: a meta-analysis of studies comparing the experience of parenting stress in parents of children with and without autism spectrum disorder. J Autism Dev Disord 43 (3):629-642. doi:10.1007/s10803-012-1604-y 
4. Lee GK, Lopata C, Volker MA, Thomeer ML, Nida RE, Toomey JA, Chow SY, Smerbeck AM (2009) Health-related quality of life of parents of children with high-functioning autism spectrum disorders. Focus on Autism and Other Developmental Disabilities 24 (4):227-239. doi:10.1177/1088357609347371

5. Lyons AM, Leon SC, Phelps CER, Dunleavy AM (2010) The impact of child symptom severity on stress among parents of children with ASD: The moderating role of coping styles. Journal of Child and Family Studies 19 (4):516-524. doi:10.1007/s10826-009-9323-5

6. Cooper CE, McLanahan SS, Meadows SO, Brooks-Gunn J (2009) Family structure transitions and maternal parenting stress. J Marriage Fam 71 (3):558-574. doi:10.1111/j.1741-3737.2009.00619.x

7. Lacharité C, Ethier L, Piché C (1992) Parental stress in mothers of preschool children: validation and Quebec norms for the Parental Stress Inventory. Sante Ment Que 17 (2):183-203

8. Abidin RR (1992) The Determinants of Parenting Behavior. Journal of Clinical Child Psychology 21 (4):407412. doi:10.1207/s15374424jccp2104_12

9. Ekas NV, Whitman TL (2011) Adaptation to daily stress among mothers of children with an autism spectrum disorder: The role of daily positive affect. J Autism Dev Disord 41 (9):1202-1213

10. Estes A, Munson J, Dawson G, Koehler E, Zhou X-H, Abbott R (2009) Parenting stress and psychological functioning among mothers of preschool children with autism and developmental delay. Autism 13 (4):375-387. doi:10.1177/1362361309105658

11. Higgins DJ, Bailey SR, Pearce JC (2005) Factors associated with functioning style and coping strategies of families with a child with an autism spectrum disorder. Autism 9 (2):125-137. doi:10.1177/1362361305051403 12. Pastor-Cerezuela G, Fernández-Andrés MI, Tárraga-Mínguez R, Navarro-Peña JM (2016) Parental Stress and ASD: Relationship with Autism Symptom Severity, IQ, and Resilience. Focus on Autism and Other Developmental Disabilities 31 (4):300-311. doi:10.1177/1088357615583471

13. Pinto Costa A, Steffgen G, Ferring D (2017) Contributors to well-being and stress in parents of children with autism spectrum disorder. Research in Autism Spectrum Disorders. doi:10.1016/j.rasd.2017.01.007

14. Mugno D, Ruta L, D'Arrigo VG, Mazzone L (2007) Impairment of quality of life in parents of children and adolescents with pervasive developmental disorder. Health Qual Life Outcomes 5:22. doi:10.1186/1477-7525-522

15. Parish SL, Seltzer MM, Greenberg JS, Floyd F (2004) Economic implications of caregiving at midlife: comparing parents with and without children who have developmental disabilities. Ment Retard 42 (6):413-426. doi:10.1352/0047-6765(2004)42<413:EIOCAM>2.0.CO;2

16. Pozo P, Sarriá E, Brioso A (2014) Family quality of life and psychological well-being in parents of children with autism spectrum disorders: a double ABCX model. J Intellect Disabil Res 58 (5):442-458.

doi:10.1111/jir.12042

17. Benson PR (2010) Coping, distress, and well-being in mothers of children with autism. Research in Autism Spectrum Disorders 4 (2):217-228. doi:10.1016/j.rasd.2009.09.008

18. Twoy R, Connolly PM, Novak JM (2007) Coping strategies used by parents of children with autism. Journal of the American Academy of Nurse Practitioners 19 (5):251-260. doi:10.1111/j.1745-7599.2007.00222.x

19. Lazarus RS, Folkman S (1984) Stress, Appraisal, and Coping. Springer Publishing Company,

20. Folkman S, Lazarus RS (1980) An Analysis of Coping in a Middle-Aged Community Sample. J Health Soc Behav 21 (3):219-239. doi:10.2307/2136617

21. Folkman S, Moskowitz JT (2004) Coping: pitfalls and promise. Annu Rev Psychol 55:745-774. doi:10.1146/annurev.psych.55.090902.141456

22. Bruchon-Schweitzer M (2002) Psychologie de la santé: modèles, concepts et méthodes. Dunod, 23. Vasilopoulou E, Nisbet J (2016) The quality of life of parents of children with autism spectrum disorder: A systematic review. Research in Autism Spectrum Disorders 23:36-49. doi:10.1016/j.rasd.2015.11.008 24. Lai WW, Oei TPS (2014) Coping in parents and caregivers of children with autism spectrum disorders (ASD): A review. Review Journal of Autism and Developmental Disorders 1 (3):207-224

25. von Elm E, Altman DG, Egger M, Pocock SJ, Gøtzsche PC, Vandenbroucke JP, Initiative S (2014) The Strengthening the Reporting of Observational Studies in Epidemiology (STROBE) Statement: guidelines for reporting observational studies. Int J Surg 12 (12):1495-1499. doi:10.1016/j.ijsu.2014.07.013

26. Law MC, MacDermid J (2008) Evidence-based Rehabilitation: A Guide to Practice. SLACK Incorporated, 27. Luque Salas B, Yáñez Rodríguez V, Tabernero Urbieta C, Cuadrado E (2017) The role of coping strategies and self-efficacy as predictors of life satisfaction in a sample of parents of children with autism spectrum disorder. Psicothema 29 (1):55-60

28. Benson PR (2014) Coping and psychological adjustment among mothers of children with ASD: An accelerated longitudinal study. J Autism Dev Disord 44 (8):1793-1807. doi:10.1007/s10803-014-2079-9 29. Carter AS, de L. Martínez-Pedraza F, Gray SAO (2009) Stability and individual change in depressive symptoms among mothers raising young children with ASD: Maternal and child correlates. Journal of Clinical Psychology 65 (12):1270-1280. doi:10.1002/jclp.20634 
30. Dardas LA, Ahmad MM (2015) Coping strategies as mediators and moderators between stress and quality of life among parents of children with autistic disorder. Stress And Health: Journal Of The International Society For The Investigation Of Stress 31 (1):5-12. doi:10.1002/smi.2513

31. Rayan A, Ahmad M (2017) Psychological Distress in Jordanian Parents of Children with Autism Spectrum Disorder: The Role of Positive Reappraisal Coping. Arch Psychiatr Nurs 31 (1):38-42.

doi:10.1016/j.apnu.2016.07.017

32. Wang J, Hu Y, Wang Y, Qin X, Xia W, Sun C, Wu L, Wang J (2013) Parenting stress in Chinese mothers of children with autism spectrum disorders. Social Psychiatry and Psychiatric Epidemiology 48 (4):575-582.

doi:10.1007/s00127-012-0569-7

33. Cappe E, Wolff M, Bobet R, Adrien J-L (2011) Quality of life: A key variable to consider in the evaluation of adjustment in parents of children with autism spectrum disorders and in the development of relevant support and assistance programmes. Quality of Life Research: An International Journal of Quality of Life Aspects of Treatment, Care \& Rehabilitation 20 (8):1279-1294. doi:10.1007/s11136-011-9861-3

34. Dabrowska A, Pisula E (2010) Parenting stress and coping styles in mothers and fathers of pre-school children with autism and Down syndrome. Journal of Intellectual Disability Research 54 (3):266-280. doi:10.1111/j.1365-2788.2010.01258.x

35. Ji B, Zhao I, Turner C, Sun M, Yi R, Tang S (2014) Predictors of health-related quality of life in Chinese caregivers of children with autism spectrum disorders: A cross-sectional study. Arch Psychiatr Nurs 28 (5):327332. doi:10.1016/j.apnu.2014.06.001

36. Lai WW, Goh TJ, Oei TPS, Sung M (2015) Coping and well-being in parents of children with autism spectrum disorders (ASD). J Autism Dev Disord 45 (8):2582-2593. doi:10.1007/s10803-015-2430-9

37. Pisula E, Kossakowska Z (2010) Sense of coherence and coping with stress among mothers and fathers of children with autism. J Autism Dev Disord 40 (12):1485-1494. doi:10.1007/s10803-010-1001-3

38. Folkman S, Lazarus RS (1988) Coping as a mediator of emotion. Journal of Personality and Social Psychology 54 (3):466

39. Cousson F, Bruchon-Schweitzer M, Quintard B, Nuissier J (1996) Analyse multidimensionnelle d'une échelle de coping: validation française de la W.C.C. (Ways of Coping Checklist). = Multidimensional analysis of a coping scale: The French validation of the Ways of Coping Checklist. Psychologie Française 41 (2):155-164 40. Vitaliano PP, Russo J, Carr JE, Maiuro RD, Becker J (1985) The Ways of Coping Checklist: Revision and Psychometric Properties. Multivariate Behav Res 20 (1):3-26. doi:10.1207/s15327906mbr2001_1

41. Carver CS, Scheier MF, Weintraub JK (1989) Assessing coping strategies: A theoretically based approach. Journal of Personality and Social Psychology 56 (2):267-283. doi:10.1037/0022-3514.56.2.267

42. Carver CS (1997) You want to measure coping but your protocol's too long: Consider the Brief COPE. International Journal of Behavioral Medicine 4 (1):92-100. doi:10.1207/s15327558ijbm0401_6

43. Hastings RP, Kovshoff H, Brown T, Ward NJ, Espinosa FD, Remington B (2005) Coping strategies in mothers and fathers of preschool and school-age children with autism. Autism 9 (4):377-391.

doi: $10.1177 / 1362361305056078$

44. Xie Y (1998) Reliability and validity of the simplified Coping Style Questionnaire. . Chinese Journal of Clinical Psychology 6 (2):114-115

45. Endler NS, Parker JDA (1990) Coping Inventory for Stressful Situations: CISS. Multi-Health Systems, 46. Tobin DL, Holroyd KA, Reynolds RV, Wigal JK (1989) The hierarchical factor structure of the Coping Strategies Inventory. Cognitive therapy and research 13 (4):343-361

47. Cano García FJ, Rodríguez Franco L, García Martínez J (2007) Adaptación española del Inventario de Estrategias de Afrontamiento. Spanish version of the Coping Strategies Inventory 35 (1):29-39

48. Garnefski N, Kraaij V, Spinhoven P (2002) Manual for the use of the Cognitive Emotion Regulation Questionnaire. Leiderdorp, The Netherlands: DATEC

49. Antonovsky A (1987) Unraveling the mystery of health: How people manage stress and stay well. JosseyBass,

50. Antonovsky A (1998) The sense of coherence. Stress, Coping, and Health in Families: Sense of Coherence and Resiliency $1: 1$

51. Yatchmenoff DK, Koren PE, Friesen BJ, Gordon LJ, Kinney RF (1998) Enrichment and Stress in Families Caring for a Child with a Serious Emotional Disorder. Journal of Child and Family Studies 7 (2):129-145.

doi:10.1023/A:1022935014502

52. Ferguson E, Matthews G, Cox T (1999) The Appraisal of Life Events (ALE) scale: Reliability and validity. British Journal of Health Psychology 4 (Part 2):97-116. doi:10.1348/135910799168506

53. Holroyd J (1987) Questionnaire on Resources and Stress: For Families with Chronically Ill Or Handicapped Members:[QRS]. Clinical Psychology Publishing Company,

54. Abidin RR (1995) Manual for the parenting stress index. Odessa, FL: Psychological Assessment Resources 
55. Lovibond PF, Lovibond SH (1995) The structure of negative emotional states: Comparison of the Depression Anxiety Stress Scales (DASS) with the Beck Depression and Anxiety Inventories. Behaviour research and therapy $33(3): 335-343$

56. Whoqol G (1998) Development of the World Health Organization WHOQOL-BREF quality of life assessment. Psychol Med 28 (3):551-558

57. Cronbach LJ (1951) Coefficient alpha and the internal structure of tests. psychometrika 16 (3):297-334 58. Myers BJ, Mackintosh VH, Goin-Kochel RP (2009) “My greatest joy and my greatest heart ache:” Parents' own words on how having a child in the autism spectrum has affected their lives and their families' lives.

Research in Autism Spectrum Disorders 3 (3):670-684. doi:10.1016/j.rasd.2009.01.004

59. Wang P, Michaels CA, Day MS (2011) Stresses and coping strategies of Chinese families with children with autism and other developmental disabilities. J Autism Dev Disord 41 (6):783-795

60. Matud MP (2004) Gender differences in stress and coping styles. Personality and individual differences 37

(7):1401-1415

61. Ptacek JT, Smith RE, Dodge KL (1994) Gender differences in coping with stress: When stressor and appraisals do not differ. Personality and social psychology bulletin 20 (4):421-430

62. Meléndez JC, Mayordomo T, Sancho P, Tomás JM (2012) Coping strategies: Gender differences and development throughout life span. Span J Psychol 15 (3):1089-1098

63. Allik H, Larsson J-O, Smedje H (2006) Health-related quality of life in parents of school-age children with Asperger syndrome or high-functioning autism. Health Qual Life Outcomes 4 (1):1

64. Mak WW, Ho AH, Law RW (2007) Sense of coherence, parenting attitudes and stress among mothers of children with autism in Hong Kong. Journal of Applied Research in Intellectual Disabilities 20 (2):157-167

65. Pottie CG, Ingram KM (2008) Daily stress, coping, and well-being in parents of children with autism: A multilevel modeling approach. Journal of family psychology 22 (6):855

66. Smith LE, Seltzer MM, Tager-Flusberg H, Greenberg JS, Carter AS (2008) A comparative analysis of wellbeing and coping among mothers of toddlers and mothers of adolescents with ASD. J Autism Dev Disord 38 (5):876-889. doi:10.1007/s10803-007-0461-6

67. Abbeduto L, Seltzer MM, Shattuck P, Krauss MW, Orsmond G, Murphy MM (2004) Psychological wellbeing and coping in mothers of youths with autism, Down syndrome, or fragile X syndrome. Am J Ment Retard 109 (3):237-254. doi:10.1352/0895-8017(2004)109<237:PWACIM>2.0.CO;2

68. Baghdadli A, Pry R, Michelon C, Rattaz C (2014) Impact of autism in adolescents on parental quality of life. Quality of Life Research: An International Journal of Quality of Life Aspects of Treatment, Care \& Rehabilitation 23 (6):1859-1868. doi:10.1007/s11136-014-0635-6

69. Hall HR, Graff JC (2011) The relationships among adaptive behaviors of children with autism, family support, parenting stress, and coping. Issues in comprehensive pediatric nursing 34 (1):4-25

70. Kuhlthau K, Payakachat N, Delahaye J, Hurson J, Pyne JM, Kovacs E, Tilford JM (2014) Quality of life for parents of children with autism spectrum disorders. Research in Autism Spectrum Disorders 8 (10):1339-1350 
Figure 1 Quality assessment criteria

\section{Complete}

Partially

Imprecise

2

1 0

\section{Introduction}

Justification of the study in the actual context

Clear and well describe aims

Accurate hypothesis

\section{Method}

Replicable protocol

Population

Inclusion-exclusion criteria shown

Participants number in each group shown

Non-participation raison shown

Accurate population characteristics

Variables

Tools presentation

Tools relevance

Data analyze

Justification of sample size

Results

Appropriate analyze plan

Clear result presentation

\section{Discussion}

Most result shown and relevant interpretation

Result discussed according to the literature

Limitations shown

Relevant conclusion

\section{Others informations}

Conflict of interest 
Figure 2 Flowchart for systematic review

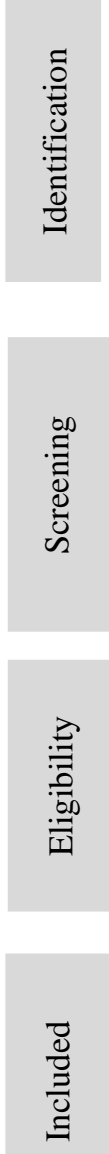

Articles identified through database searching $(\mathrm{n}=156)$

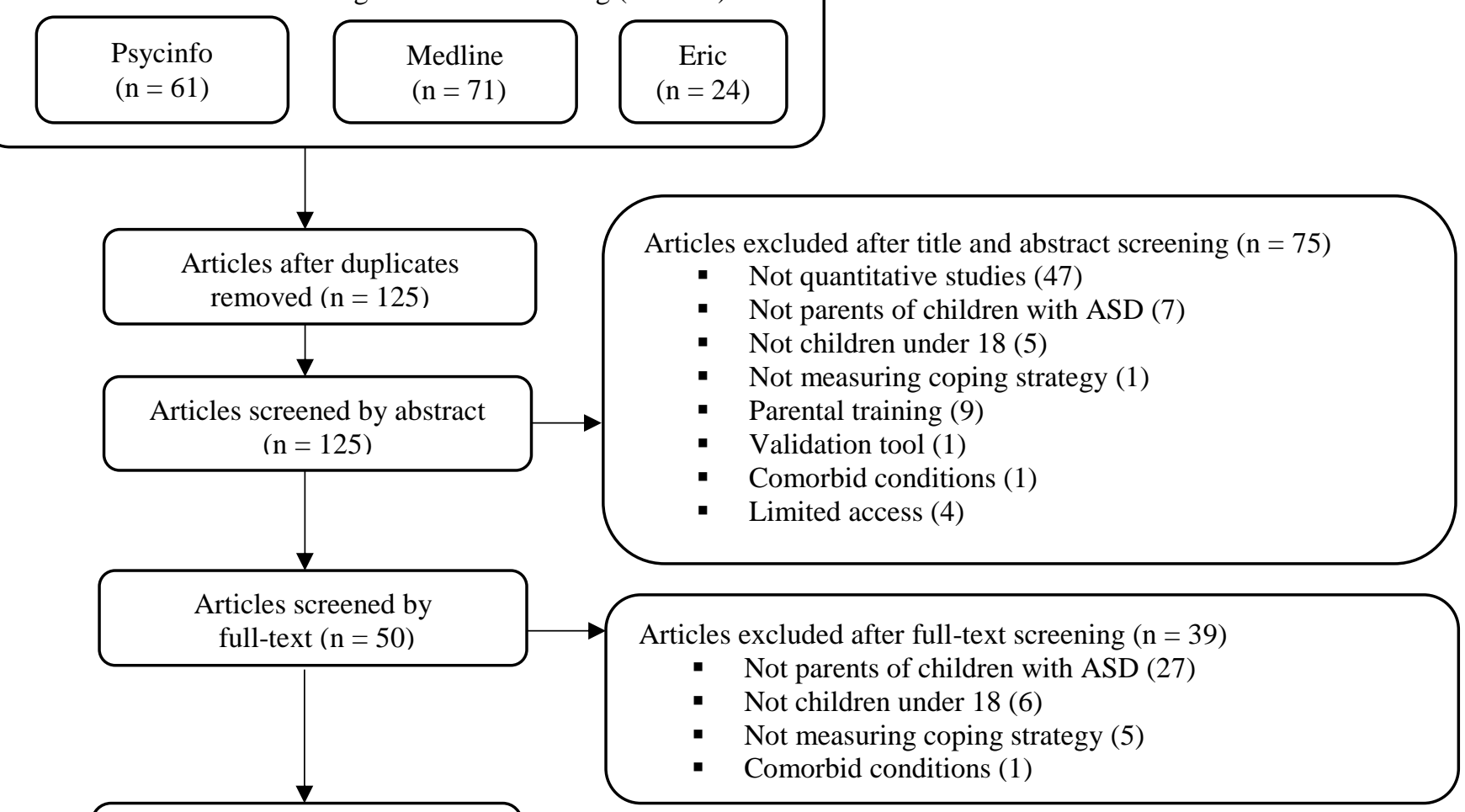

Studies included in the review $(\mathrm{n}=11)$ 


\section{Table 1}

Participant characteristics

PDD-NOS: Pervasive Developmental Disorder - Not Otherwise Specified; AS: Asperger's Syndrome; ASD: Autism Spectrum Disorders; ADI-R: Autism Diagnostic InterviewRevised; DSM-IV-TR: Diagnostic and Statistical Manual of Mental Disorders Fourth Edition Text Revision; ICD-10: International Statistical Classification of Diseases and Related Health Problems Tenth Edition; ADOS: Autism Diagnostic Observation Schedule; COPE: Coping Orientations to Problems Experienced ; WCC-R: Ways of Coping Checklist Revised ; CISS: Coping Inventory for Stressful Situations; SCSQ: Simplified Coping Style Questionnaire; CSI: Coping Strategy Inventory; WCQ: Ways of Coping Questionnaire; CERQ: Cognitive Emotion Regulation Questionnaire

\begin{tabular}{|c|c|c|c|c|c|c|c|c|c|}
\hline Study & $\begin{array}{l}\text { n (cases/ } \\
\text { control/ } \\
\text { other } \\
\text { diagnosis) }\end{array}$ & $\begin{array}{l}\text { Mothers/ } \\
\text { fathers/ } \\
\text { other } \\
\text { caregivers }\end{array}$ & $\begin{array}{l}\text { Mean age of } \\
\text { parents or other } \\
\text { caregivers } \\
\text { (standard } \\
\text { deviation) }\end{array}$ & $\begin{array}{l}\text { Marital } \\
\text { status (\% } \\
\text { married) }\end{array}$ & $\begin{array}{l}\text { Employment } \\
\text { status (\% } \\
\text { employed) }\end{array}$ & $\begin{array}{l}\text { Mean age of } \\
\text { children (standard } \\
\text { deviation) }\end{array}$ & Diagnosis & $\begin{array}{l}\text { Diagnosis } \\
\text { establishment }\end{array}$ & $\begin{array}{l}\text { Coping } \\
\text { questionnaires }\end{array}$ \\
\hline $\begin{array}{l}\text { Benson (2014) } \\
\text { [28] }\end{array}$ & $\begin{array}{l}113 \\
(113 / 0 / 0)\end{array}$ & $113 / 0 / 0$ & $42(5.2)$ & $81 \%$ & $60.60 \%$ & $8.6(1.5)$ & $\begin{array}{l}33 \% \text { autism, } \\
27 \% \text { PDD- } \\
\text { NOS, } 12 \% \text { AS, } \\
28 \% \\
\text { unspecified } \\
\text { ASD }\end{array}$ & ADI-R & Brief COPE \\
\hline $\begin{array}{l}\text { Cappe et al. (2011) } \\
\text { [33] }\end{array}$ & $\begin{array}{l}160 \\
(160 / 0 / 0)\end{array}$ & $113 / 47 / 0$ & $46(8.85)$ & $60 \%$ & ND & $14.25(8)$ & $\begin{array}{l}73.73 \% \\
\text { autism, } \\
8.47 \% \text { PDD- } \\
\text { NOS, } 17.80 \% \\
\text { AS }\end{array}$ & $\begin{array}{l}\text { DSM-IV-TR } \\
\text { ICD-10 }\end{array}$ & WCC-R \\
\hline $\begin{array}{l}\text { Carter et al. (2009) } \\
\text { [29] }\end{array}$ & $\begin{array}{l}143 \\
(143 / 0 / 0)\end{array}$ & $143 / 0 / 0$ & $36.42(5.03)$ & $92 \%$ & ND & $2.36(0.3)$ & ASD & $\begin{array}{l}\text { ADI-R } \\
\text { ADOS }\end{array}$ & COPE \\
\hline $\begin{array}{l}\text { Dabrowska \& } \\
\text { Pisula (2010) [34] }\end{array}$ & $\begin{array}{l}162 \\
(51 / 57 / 54)\end{array}$ & $\begin{array}{l}\text { autism: } \\
26 / 25 / 0 \\
\text { control: } \\
28 / 29 / 0 \\
\text { down } \\
\text { syndrome: } \\
27 / 27 / 0\end{array}$ & $\begin{array}{l}\text { autism: } \\
\text { mothers: } \\
30.7(4.1) \\
\text { fathers: } \\
34.4 \text { (5.0) } \\
\text { control: } \\
\text { mothers: } \\
31 \text { (4.4) } \\
\text { fathers: }\end{array}$ & $\begin{array}{l}\text { autism: } 94.1 \% \\
\text { control: } \\
96.5 \% \\
\text { down } \\
\text { syndrome: } \\
94.5 \%\end{array}$ & $\begin{array}{l}\text { autism: } 64.7 \% \\
\text { control: } 91.2 \% \\
\text { down } \\
\text { syndrome: } \\
75.9 \%\end{array}$ & $\begin{array}{l}\text { autism: } \\
\text { girls: } \\
4.7(1.34) \\
\text { boys: } \\
4.8(1.35) \\
\text { control: } \\
\text { girls: } \\
4.9 \text { (1.42) } \\
\text { boys: }\end{array}$ & $\begin{array}{l}\text { autism }(\mathrm{n}= \\
26) \\
\text { down } \\
\text { syndrome ( } \mathrm{n}= \\
27)\end{array}$ & DSM-IV & CISS \\
\hline
\end{tabular}




\begin{tabular}{|c|c|c|c|c|c|c|c|c|c|}
\hline & & & $\begin{array}{l}34.6(4.3) \\
\text { down syndrome: } \\
\text { mothers: } \\
32.8(6.1) \\
\text { fathers: } \\
34.9(6.1)\end{array}$ & & & $\begin{array}{l}4.2(1.23) \\
\text { down syndrome: } \\
\text { girls: } \\
4.3(1.48) \\
\text { boys: } \\
4.3(1.58)\end{array}$ & & & \\
\hline $\begin{array}{l}\text { Dardas \& Ahmad } \\
\text { (2015) [30] }\end{array}$ & $\begin{array}{l}184 \\
(184 / 0 / 0)\end{array}$ & $114 / 70 / 0$ & $37(7.6)$ & $96.70 \%$ & $44 \%$ & $6.3(3)$ & $\begin{array}{l}\text { autistic } \\
\text { disorder }\end{array}$ & DSM-IV & WCC-R \\
\hline Ji et al. (2014) [35] & $\begin{array}{l}278 \\
(278 / 0 / 0)\end{array}$ & $199 / 30 / 44$ & $35.22(9.59)$ & $92.30 \%$ & $31.50 \%$ & $4.81(2.01)$ & ASD & $\begin{array}{l}\text { DSM-IV } \\
\text { ICD-10 }\end{array}$ & SCSQ \\
\hline $\begin{array}{l}\text { Lai et al. (2015) } \\
\text { [36] }\end{array}$ & $\begin{array}{l}136 \\
(73 / 63 / 0)\end{array}$ & $\begin{array}{l}\text { autism: } \\
58 / 15 / 0 \\
\text { control: } \\
52 / 11 / 0\end{array}$ & $\begin{array}{l}\text { autism: } \\
46.10(5.5) \\
\text { AS: } \\
46.0(4.36) \\
P D D-N O S: \\
48.30(5.73) \\
\text { control: } \\
41.0(6.23)\end{array}$ & ND & $\begin{array}{l}\text { autism: } 68.8 \% \\
\text { control: } 63.5 \%\end{array}$ & $\begin{array}{l}\text { autism: } \\
14.10(3.6) \\
\text { AS: } \\
12.90(4.0) \\
\text { PDD-NOS: } \\
13.25(2.72) \\
\text { control: } \\
10.8(3.19)\end{array}$ & $\begin{array}{l}59 \% \text { autism } \\
20.5 \% \text { AS } \\
20.5 \% \text { PDD- } \\
\text { NOS }\end{array}$ & $\begin{array}{l}\text { ADI-R } \\
\text { ADOS }\end{array}$ & Brief COPE \\
\hline $\begin{array}{l}\text { Luque Salas et al. } \\
\text { (2017) [27] }\end{array}$ & $\begin{array}{l}129 \\
(129 / 0 / 0)\end{array}$ & $65 / 64 / 0$ & $\begin{array}{l}\text { mothers: } \\
39.5(4.85) \\
\text { fathers: } \\
41.62(5.42)\end{array}$ & $94 \%$ & $43.4 \%$ & $\begin{array}{l}\text { boys: } \\
7.46(3.07) \\
\text { girls: } \\
6.95(3.15)\end{array}$ & $\begin{array}{l}\text { autistic } \\
\text { disorder } \\
\text { asperger } \\
\text { PDD-NOS }\end{array}$ & $\begin{array}{l}\text { ADOS } \\
\text { ADI-R } \\
\text { ICD-10 }\end{array}$ & CSI \\
\hline $\begin{array}{l}\text { Pisula \& } \\
\text { Kossakowska } \\
\text { (2010) [37] }\end{array}$ & $\begin{array}{l}110 \\
(52 / 58 / 0)\end{array}$ & $\begin{array}{l}\text { autism: } \\
26 / 26 / 0 \\
\text { control: } \\
29 / 29 / 0\end{array}$ & $\begin{array}{l}\text { autism: } \\
\text { mothers: } \\
34(5.5) \\
\text { fathers: } \\
36(5.6) \\
\text { control: } \\
\text { mothers: } \\
32(5.3) \\
\text { fathers: } \\
35 \text { (6.9) }\end{array}$ & $100 \%$ & ND & $\begin{array}{l}\text { autism: } \\
5.12(0.9) \\
\text { control: } \\
4.67(1.2)\end{array}$ & autism & ICD-10 & WCQ \\
\hline $\begin{array}{l}\text { Rayan \& Ahmad } \\
\text { (2017) [31] }\end{array}$ & $104 / 0 / 0$ & $73 / 31 / 0$ & 36 & $98 \%$ & $30 \%$ & - & TSA & DSM 5 & CERQ \\
\hline
\end{tabular}


Wang et al. (2013) 150

[32]
$150 / 0 / 0$

(150/0/0)
32.39 (4.50)
$92.70 \%$

$73.30 \%$

$5.15(1.72)$

$96 \%$ autism

DSM-IV

SCSQ

$3.3 \%$ PDD-

NOS

$0.6 \%$ AS 
Table 2 Link between coping and stress

\begin{tabular}{|c|c|c|c|c|c|c|c|c|c|c|}
\hline & \multicolumn{9}{|c|}{ Coping } \\
\hline & & $\begin{array}{l}\text { Problem- } \\
\text { focused } \\
\text { coping }\end{array}$ & $\begin{array}{l}\text { Emotion- } \\
\text { focused } \\
\text { coping }\end{array}$ & Engagement & Disengagement & Distraction & $\begin{array}{l}\text { Cognitive } \\
\text { reframing }\end{array}$ & $\begin{array}{l}\text { Negative } \\
\text { coping }\end{array}$ & $\begin{array}{l}\text { Active } \\
\text { coping }\end{array}$ & $\begin{array}{l}\text { Positive } \\
\text { reappraisal }\end{array}$ \\
\hline $\begin{array}{l}\text { Cappe et al. } \\
\text { (2011) [33] }\end{array}$ & & $\begin{array}{l}\text { Challenge } \\
r=0.38^{*}\end{array}$ & $\begin{array}{l}\text { Threat and } \\
\quad \text { loss } \\
\mathrm{r}=0.39^{*}\end{array}$ & & & & & & & \\
\hline $\begin{array}{c}\text { Dabrowska } \\
\text { \& Pisula } \\
(2010) \text { [27] }\end{array}$ & $\infty$ & & $\begin{array}{c}\text { Parental } \\
\text { stress } \\
\beta= \\
0.531^{* * *}\end{array}$ & & & & & & & \\
\hline $\begin{array}{c}\text { Benson } \\
(2014)[30]\end{array}$ & $\stackrel{D}{\mathscr{\Xi}}$ & & & $\begin{array}{c}\text { Stress } \\
\text { proliferation } \\
\beta=0.013^{* *}\end{array}$ & $\begin{array}{c}\text { Stress } \\
\text { proliferation } \\
\beta=0.057^{* * *}\end{array}$ & $\begin{array}{c}\text { Stress } \\
\text { proliferation } \\
\beta= \\
0.033^{* * *}\end{array}$ & $\begin{array}{c}\text { Stress } \\
\text { proliferation } \\
\text { n.s. }\end{array}$ & & & \\
\hline $\begin{array}{l}\text { Wang et al. } \\
\text { (2013) [34] }\end{array}$ & & & & & & & & $\begin{array}{l}\text { Parental } \\
\text { stress } \\
\mathrm{r}= \\
0.195^{*}\end{array}$ & $\begin{array}{c}\text { Parental } \\
\text { stress } \\
\mathrm{r}=- \\
0.174^{*}\end{array}$ & \\
\hline $\begin{array}{c}\text { Rayan \& } \\
\text { Ahmad } \\
(2017)[29]\end{array}$ & & & & & & & & & & $\begin{array}{c}\text { Parental } \\
\text { stress } \\
\beta=- \\
0.21 * *\end{array}$ \\
\hline
\end{tabular}

$* \mathrm{p}<0.05, * * \mathrm{p}<0.01, * * * \mathrm{p}<0.001$, n.s.: not significant

Table 3 Link between coping and quality of life according to Cappe et al. (2011) [33]

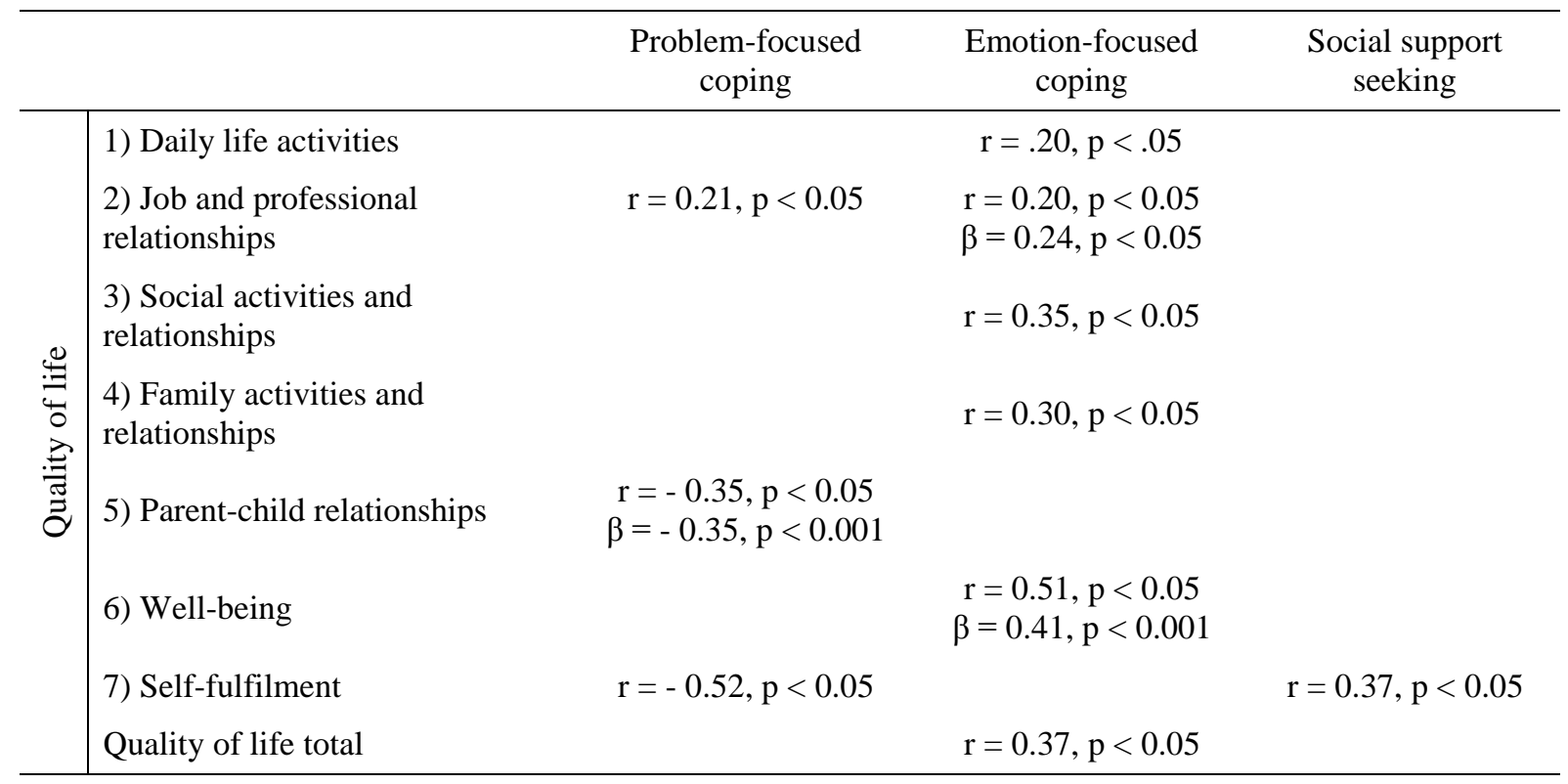

